\title{
7 Young people's recommendations and actions for schools/teachers, parents/guardians, and social media companies
}

\author{
Victoria A. Goodyear, Hannah Wood, \\ and Kathleen M. Armour
}

\section{Chapter overview}

This chapter introduces, illustrates, and analyses the finding that parent/ guardians and schools/ teachers are currently ill-equipped to support young people to make informed decisions about their engagement with health-related social media. Data shows that support from adults is welcomed by young people, but that adults require a better understanding of the complex and dynamic ways in which young people use social media. Peer-based support is also important, given young people's contextual knowledge about social media. The case suggests that adults and peers can help young people to choose how to respond to health-related information and how to determine credible information.

\section{Chapter structure and underpinning evidence}

This chapter is organised into three main sections. In Section One, a narrative is presented to tell the story of young people's frustrations with how adults interpret their uses of social media. The narrative was constructed from an extensive data set (as detailed in Chapter 1) and illustrates the voices and experiences of over 1,300 young people in the UK. The narrative is presented in the form of a WhatsApp conversation, that one group of young people selected as a relevant way of communicating their experiences of social media to adults. Direct quotes from the data are shown in quotation marks. In Section Two, an overview of how young people perceive they should be supported by adults to navigate and use health-related material on social media is provided. These recommendations and actions were constructed from 50 young people during a one-day workshop (as detailed in Chapter 1). The young people watched videos of the case study narratives presented in Chapters 2-6 and were asked to create a response for adults. Data were drawn from resources young people created such as radio or TV interview, podcast, video/movie, or a newspaper article. Direct quotes from the data are shown in quotation marks, and pseudonyms are used. Quotes are also used from the resources young people created and are referred to as artefacts. In Section Three, the key messages that emerge from the narrative and the workshop are summarised. 


\section{Section One: young people's narrative - Kelly, Yaz, Leah, James, and Jess}

'Kelly', 'Yaz', 'Leah', 'James', and 'Jess' (from Chapters 2-6) were members of a WhatsApp group. Despite the group members having different experiences of health-related social media (see Table 7.1), they all used social media to interact with friends.

The WhatsApp group was named Pengting, a word used by young people to say that someone is attractive. One interpretation of the WhatsApp group's name is that the discussions on this social media site would all be about body image. From the name, it could be assumed that the group members are obsessed with their bodies being perfect. This perspective is, however, the adult understanding of the group name. The WhatsApp group members had named the group Pengting as a joke. Pengting is just one of the latest words young people use and is a throwaway term. Pengting is similar to terms such as 'sick' that means good not poorly; 'bare' that means really or lots of; and 'dench' that means the same

Table 7.1 The different ways in which Kelly, Yaz, Leah, James, and Jess experienced health-related social media

Kelly Kelly uses social media to stay connected with her friends. She does not search for information about health and wellbeing on social media, but, through posts her friends like and automatically sourced accounts, Kelly sees large amounts of health and wellbeing-related content. Through using social media to stay connected with her friends, Kelly has learnt about many health-related workouts, diets, and products, including FitTea.

Yaz Yaz uses social media to find quick and easy information that is relatable to him and relevant to his perceived needs. Yaz relates to the body transformation videos that he sees on social media as he wants to become more muscular. Yaz has started to act on the videos that he sees on social media, despite the videos being harmful for his physical development.

Leah Leah uses social media to look at and share posts made by her friends. Young people Leah's age post pictures of their bodies on social media to get attention, but Leah is too self-conscious to post pictures of her body. Leah compares her body image to the pictures of her friends on social media and feels a level of peer pressure to look a certain way.

James James is addicted to getting a high number of likes and followers from his posts to social media. To get a high number of likes and followers James posts selfies and engages with competitions focused on who can get the most likes and followers. His behaviour on social media is very self-focused and the tactics James used to win the 'likes' competition negatively impacted on another girl's wellbeing at his school.

Jess Jess admires 'fake celebrities' on social media and wants to look like them. On social media, Jess is bombarded with information about how she can change her body image to look like the 'fake celebrities'. Jess finds it difficult to determine what information is legitimate. Jess used Photoshop to try and create the perfect picture but considered using a waist trainer instead when her post didn't receive enough comments. 
as sick and is used to identify something as good. The problem the members of the WhatsApp group experience, like many other young people their age, is that adults don't really understand the language they use to communicate and the ways in which they use social media. There is an overwhelming tendency in adults to assume the worst and because they don't understand social media, almost every word or post is perceived as a risk.

This narrative tells the story of the Pengting WhatsApp group's frustrations with adults' limited understandings of the ways in which they use social media. The narrative is told through the Pengting group's WhatsApp messages to reflect one of the ways in which the young people wanted to communicate their message and because this form of dialogue also reflects the contemporary ways in which young people interact with each other.

\section{The WhatsApp messages}

The messages on WhatsApp were in response to recent events at school about social media and health. It had been announced in the previous week by the Pengting group's Head of Year that there would be an assembly on social media. This assembly was the third that term on the same topic. This time, however, the assembly was going to be about social media and health. One of the girls at school had started to suffer from anorexia because of something she had seen on social media and so the headteacher had initiated assemblies for all year groups.

'Ping!' Kelly's (see Table 7.1) WhatsApp alert went off ... and again ... and again. She looked at her phone and had loads of unread messages in the 'Pengting' group. Leah (see Table 7.1) had sent a series of messages and she clearly wanted to vent about the social media and health assembly tomorrow. Leah was frustrated by the teachers' assumptions that, because one person had a bad experience, everyone else could be affected in the same way. Leah was also worried that the teachers were reverting to their typical protection-orientated approach and would confiscate their phones.

17:53 LEAH: As if we have a social media and health assembly tomorrow just because that Anna girl in 10RJS got 'anorexia'

17:53 LEAH: I get that she 'got affected' by social media and that people were 'skinny shaming' and 'laughing at her'. That is bad, and yeah there are 'loads of risks' but not for everyone. Not for us!!!

17:54 LEAH: They will just use it as another reason try to ban us using phones! It is always the same when something bad happens

Kelly had forgotten about the social media assembly. The assemblies on social media were a running joke. The teachers always say the 'same thing', normally reminding them all to 'put their privacy settings up' or telling them about 'cyberbullying'. The teachers perceive that they are doing a good job of protecting young people from social media. The problem is, they 'don't really talk about' the important stuff. They don't talk about 'peer pressure' (as Leah had 
experienced see Table 7.1) on social media or all of the 'perfect bodies' with which everyone in the Pengting group are bombarded. These are the real risks of social media and the assemblies aren't, therefore, perceived as relevant.

18:01 KELLY: yeah and what are they going to even say!? It is not like 'a lot of the teachers here can really help!'

18:01 KELLY: 'I have Miss Williams' ... 'I doubt she uses Snapchat everyday'

18:02 KELLY: They don't even know what we see on social media ... or what we actually look at

18:02 JAMES: क्षेत्र

James 'liked' Kelly's messages. This wasn't a surprise to Kelly as James has a habit of 'liking' everything on social media (see Table 7.1). James was in agreement with Kelly. In the WhatsApp messages James sent, he started to ridicule the teachers for trying to talk to them about social media. The teachers didn't understand the way the Pengting group, like many other young people their age, interacted on social media. Teachers often misinterpreted their interactions and behaviours, particularly when they try to second-guess what emojis ${ }^{1}$ mean. As a result, James felt that the assemblies were irrelevant to him and his uses of social media and he intended not to listen.

18:03 JAMES: Yeah 'I don't suppose they all know a lot about social media', especially the 'teachers who are more experienced' shall we say $\odot ;$

18:04 JAMES: It is pretty funny when they 'try to guess what emojis mean' and stuff though ... obviously 'it's completely wrong!'

18.05 KELLY: Yeah and even though they don't have a clue, we are always getting 'lectures' from teachers saying 'Oh, do this, do that'. It's 'quite tiring'

18.06 JAMES: ही을

18:07 KELLY: 'PSHE is boring enough already!' They don't need to make assemblies even worse

18:07 LEAH: I bet they think that because we're all on social media this one is going to be really interesting, something we'll like

18:08 JAMES: I'm just going to try and stick my headphones in tomorrow. Don't think I'll be missing out on anything that is relevant to me

Yaz (see Table 7.1) joined the WhatsApp conversation. Yaz offered a different perspective to Kelly, Leah, and James. Yaz suggested that the social media assembly was an opportunity for everyone in their school to get the same information about social media and, in turn, reduce risk-related impacts. Assemblies, he felt, could reduce the number of people suffering from anorexia because information would reach everyone. Yaz also considered that his physical education teachers could be an important source of information and social support. In physical education, teachers could guide young people to the correct workouts to use for their age and to promote health. 
18:10 YAZ: I would rather have a 'thing at school'! At least then 'everyone gets fed the same information' and there is more chance that less ppl will become anorexic coz of social media

18.11 KELLY: I completely disagree. I hate social media assemblies

18:13 YAZ: Yeah and I know you hate the assemblies Kelly ... but I reckon some of the 'younger teachers in the school' could be pretty helpful

18.14 KELLY: like who?

18:16 YAZ: 'any of our PE teachers' could be pretty good at 'making sure that people know that they are able to go to someone to talk', 'if they are feeling inadequate'.

18:17 YAZ: like with workout videos, PE teachers could help us know 'which ones to watch and which ones to do'. Workouts which are 'age appropriate'

Although the Pengting group was frustrated by the assembly on social media and health, all group members agreed that they would prefer to be told about social media in school rather than at home and by their parents. Talking to parents, as can be seen from the WhatsApp messages below, was embarrassing and uncomfortable. Collectively, the group felt that their parents did not understand how they used social media. Parents' reactions were described as extreme and their responses were unhelpful. Parents would either ban their daughter/son from using social media or laugh at the uses of social media, with very little concern of risk or harm. The Pengting group felt that neither of these responses were helpful.

18:21 YAZ: Also, much better than having to talk to my parents about it!!!!

18:21 YAZ: Can you imagine 'telling your mum about what's happened on Instagram. I don't think that's a very comfortable position to be in!'

18:22 JESS: erm no!! That would be 'just awkward'.

18:23 LEAH: not comfortable at all!! And 'if we tell our parents they would probably just ban us from using social media'

18:23 JESS: 'They love you but they're not really our age so they wouldn't understand'. Just look at how they use it! 'They are on Facebook' and post things like 'oh, I did a fun run today'!!! Imagine if we did that! Haha

18:24 LEAH: Yeah my mum is on Facebook all the time posting things like 'out for a drink with friends'.

18:24 LEAH: She sent me a friend request the other day. I'm not sure she realises that we don't go on Facebook in order to avoid parents!

18:27 JAMES: My mum 'just doesn't get it'. She doesn't understand seeing stuff like fitspiration posts can actually be 'damaging'!

18:28 JAMES: I showed them to mum and now 'every time she sees something on Facebook about somebody's fitspo or whatever, she laughs and then she shows it to me and says, "Look how funny this is",

As the WhatsApp conversation continued, most of the group agreed that teachers' and parents'/guardians' knowledge about how young people use social 
media needed to be enhanced. Adults needed to: understand the contemporary pressures in young people's lives; be aware of the varying risks young people are exposed to on social media; and know strategies for how young people manage and cope with pressures and risks on social media. The Pengting group felt that this type of knowledge would provide adults with a better understanding of what young people 'actually do' on social media and would strengthen adults' ability to offer support that is relevant and effective.

18:40 KELLY: But maybe our parents should be 'informed'. Maybe someone has to tell them about the 'problems of our generation'. They 'know you best' and are 'the ones who know what's good for you'

18:42 KELLY: I know that Anna getting anorexia doesn't happen to everyone on social media but if our parents are 'made aware of the risks', maybe they can 'check if we are struggling!' Maybe that would mean no more stupid assemblies, talking about everything in 'stark contrast to what we actually do'!

18:50 YAZ: Yeah maybe adults need to be educated to understand what young people deal with on social media.

James offered a different perspective. James stressed that social media companies have a role to play in supporting young people to deal with pressure and risk. Social media companies, James highlighted, could filter and restrict what people can see.

19:02 JAMES: Or maybe it's the 'social media themselves' that should be doing something!

19:03 JAMES: It is them who are 'letting people do this'. There should be 'age restrictions' for inappropriate material; they should 'limit' the stuff we can see.

19:04 JAMES: Why do people our age need to know about FitTea!?!

19:06 KELLY: That's true! Social media companies 'can't control what people put on social media, but they can give advisory points'

19:08 JESS: Anyway, can we stop talking about school now. This has gone on way to long

The conversation finished with Jess' desire to change the focus of the conversation. The next day, the Pengting group was due to have their assembly about social media and health. It was clear from the WhatsApp messages that the young people were not looking forward to this because they felt the content would be irrelevant and would not reflect how they use social media.

\section{Narrative summary}

Young people perceive that adults over-estimate the risks of social media and this is due to a lack of understanding of the medium and the very dynamic ways 
in which young people interact. The educational support young people receive in the form of school assemblies is often deemed to be irrelevant and outdated. Young people do not feel that teachers are currently well placed to provide educational advice about social media given that they often do not occupy the same digital spaces as young people. Despite this, some young people believe school is the most appropriate setting to receive social media support and that teachers have the potential to aid young people's navigation of social media. In contrast, young people often do not feel comfortable talking to their parents about the risks of social media. In order to support young people, parents and teachers need to increase their awareness of how young people use social media, the risks they face, and how these risks are navigated. Some young people believe that social media companies have a responsibility to minimise the health-related risks of using social media.

\section{Section Two: young people's recommendations and actions for adults}

To better understand how young people could be supported to participate in social media, the authors of this book hosted a one-day workshop with young people in June 2017. Fifty young people aged 13-16 from varying UK schools attended the workshop at the University of Birmingham (see Chapter 1). Young people worked in groups and watched videos of the case studies. Young people were then asked to construct artefacts that could act as a resource targeted at adults to inform them about how young people their age should be supported to use health-related social media. The young people could create different types of resources including a radio or TV interview, podcast, video/movie, or a newspaper article. Each group was also asked to decide on the main message of their constructed resource what category of adult they wanted to reach, that is, a policy maker, a health and wellbeing organisation, their head teacher, teachers, or their parents/guardians. The data highlighted two key recommendations and actions for adults.

\section{Adults' understanding of the influence of social media on young people's health and wellbeing should be improved}

Adults require a deeper understanding of how young people use and navigate health-related material on social media. This message was explicitly detailed in a number of the resources constructed by the young people. The resources aimed to increase adult awareness of the negative impacts of social media on young people's health.

The young people perceived that adults were not aware of the types of material young people saw daily and/or the influence of these images on their health and wellbeing. For example, the opening line of a constructed newspaper article stated, 'May your life be as perfect as you pretend it is on Facebook'. The constructed article, titled 'False perfections', was aimed to be an informative 
resource for parents and it focused on the need for parents to better understand the impact of filtered images on young people's perceptions of their body image. The article went on to highlight how much of the material accessed from social media can have negative impacts:

As parents of today's youth, we need to be aware of the impacts the media can have on their health and wellbeing. Over $50 \%$ of young people believe that social media is a good source of health information; Yes, this can be proved by some aspects of what they see, yet plenty can be proved to be negatively impactful.

(constructed newspaper article)

The young people perceived that adults tended to disregard the pressures they experienced in their lives. This was emphasised in another constructed newspaper article that encouraged adults to understand that social media has a powerful influence on health and wellbeing behaviours. The article also sought to educate adults as to why young people turn to social media for health-related information and highlighted that young people needed to be educated about how to make informed decisions about what health information to use or ignore.

Teenagers are under the influence of social media; this brings many negative thoughts into their minds when they could be focusing on education. Their diets seem to be based on sugary food, however, they try to fix this by having pathetic, unhealthy, un-natural drinks, such as FitTea, which is promoted by many celebs on social media. People must start educating and helping the younger generation in becoming more healthy for their wellbeing.

(constructed newspaper article)

The young people also stressed that adults need to be aware of how their own behaviours on social media impact young people. This was particularly evident in the case of celebrities and it was emphasised that celebrities need to consider the material they share. For example,

celebs should understand that the things they promote are dangerous and can influence many.

(constructed newspaper article)

Finally, the young people strongly resisted the tendency for adults to ban social media. The young people stressed that adults needed to understand that social media is a powerful learning resource and should be used to support their learning about health and wellbeing, as well as other subjects in school. For example:

Any technological device should be allowed.... We could be able to research any information, to help us quickly and easily. It's an everyday 
tactic. For example, in history you can find out information that happened in a century and now.... Using a device can help students learn and make them become more independent.

(constructed newspaper article)

Overall, the responses from young people strongly suggest that they would welcome adult support to help them navigate and use health-related social media. To do this, adults require a better understanding of: (i) the impacts of social media on young people's health and wellbeing; (ii) the types of material young people access from social media; (iii) the reasons why young people turn to social media for health information; and (iv) how social media can be an important learning resource. Adults, such as celebrities, must also understand their influence on young people through social media.

\section{Young people need to be better informed about the health-related material available on social media}

Young people considered that they required a better understanding about the health-related material that is available to them on social media in order to help them make more informed decisions about their health-related behaviours. Although adults could offer this guidance, information from young people their own age was also considered to be very important. The young people emphasised that peers were more appreciative of the pressures they experience in their lives and understood the complex ways in which youth navigate social media. In turn, a number of the constructed resources were targeted at young people, aiming to encourage them to be critical of the health-related material that they access from social media.

A key aim of some of the constructed resources was to communicate to other young people how they might be negatively impacted by the health-related information that is available on social media. A good example of this was from a video of a constructed interview, that was created by a group of young people, that aimed to highlight how a young person was demotivated by the material on body image that had been accessed from social media. The interview also emphasised it was important for schools to have an increased focus on peer pressure and body dissatisfaction.

INTERVIEWER: As a young person, has how you view yourself been changed by social media?

INTERVIEWEE: You are definitely influenced by what you see and read and I think that has changed my perception of myself, yeah ...

INTERVIEWER: Do you think school should focus more on peer pressure and body dissatisfaction?

INTERVIEWEE: Yeah I do, I think that it's an unseen issue that has occurred from social media. You do view your body differently by what you see and you get peer pressure to do certain things by your friends but also companies online. 
INTERVIEWER: What do you see more of on social media on body image, motivation or demotivation?

INTERVIEWEE: I think for me personally I see, for me anyway, demotivation. Because you will see like, I don't know, a really good model body, and you want that but you know you can't really get that.

INTERVIEWER: Like false hope?

INTERVIEWEE: Yeah it builds up your dream and stuff.

(video interview artefact)

In other constructed resources, the aim was to help young people determine what types of health-related information was credible and could be used to inform their health-related behaviours. In many of the newspaper articles, images were used to display what had been photoshopped or what information was credible. Quotes supporting the images also sought to encourage young people to be critical of the images on social media they accessed. For example, 'you don't have to be what you see' (constructed newspaper article).

The resources these young people felt should be targeted at young people also sought to provide direction and guidance on what they should do when they accessed a particular health-related post. It was emphasised that young people should block users, report users, tell somebody about their experience and/or be critical of information. One constructed video-based resource that was filmed in the format of a movie communicated these messages by using different scenarios. For example:

FEMALE: I'm going to post this on Instagram ... filter, filter, filter. Ok, so let me see how many likes and comments I have

MALE: You're fat, you're ugly, you're stupid, you're hair looks terrible FEMALE: What the hell is this!?!

NARRATOR: What happened there is that she wasn't very critical about who she was following so they were now bullying her. Always make sure that if this happens to you that you block them and report them and always tell somebody.

(constructed video artefact)

Overall, the resources constructed by young people strongly suggest that they need support to better understand the health-related information that is available on social media. Young people require an understanding of: (i) the potential negative impacts of health-related material; (ii) how to determine credible information; (iii) and how they should respond to health-related material if they experience any harm. This information should be provided to young people by young people, given their contextualised knowledge of social media. 


\title{
Section Three: key messages from the case
}

This case has illustrated that parent/guardians and schools/teachers are currently ill-equipped to support young people to make informed decisions about their engagement with health-related social media. The case argues that adults and peers can help young people to determine how to respond to health-related information and how to determine credible health-related information that they can use.

Table 7.2 Key messages on young people's recommendations for adults

Key Characteristics of Young People's Uses of Social Media for Health

\begin{abstract}
Young people believe that adults over-estimate the risks of social media. Young people do not feel that teachers are currently well placed to provide educational advice about social media given that they often do not occupy the same digital spaces as young people. Despite this, some young people believe school is the most appropriate setting to receive social media support given that it is a space that can reach all young people. School support is important as some young people do not feel comfortable talking to their parents about the risks of social media. Some young people believe that social media companies have a responsibility to control and limit what young people can see and access, and by offering advice to young people.
\end{abstract}

Young People's

Recommendations and Actions for Adults in supporting their uses of social media
Adults' understanding of the influence of social media on young people's health must be improved. Adults require a better understanding of: (i) the impacts of social media on young people's health and wellbeing; (ii) the types of material young people access from social media; (iii) the reasons why young people turn to social media for health information; and (iv) how social media can be an important learning resource. Young people also need to better informed about the health-related material available on social media in order to make better, informed decisions about their health-related behaviours. Young people require an understanding of: (i) the potential negative impacts of health-related material; (ii) how to determine credible information; (iii) and how they should respond to health-related material if they experience any harm.

\section{Note}

1 Emojis are ideograms and smileys used in electronic messages and webpages. 